later that year (Plendl, Jb. dt. Vers Anst. Luftf., 665-671; 1931).

"Ionosphere" came into use widely beginning only in the period 19321934 when Watson-Watt, Appleton, Ratcliffe, W. Dieminger, I. Ranzi, D. F. Martyn, S. K. Mitra and others began to use the word in the titles of published papers and lectures. An example of its legitimisation was the prominent use of "Ionosphere" in the Kelvin Lecture delivered at the Institution of Electrical Engineers in April 1933 by Sir Frank Smith, Secretary of the Department of Scientific and Industrial Research (Smith, Electrician, 110, 581-582; May 5, 1933). It was thus that the term began to appear in library indices and abstracting categories. It then began to be used in related

forms; the pulsing vertical incidence radar became known as the ionosonde, and ionospheric workers were sometimes known as ionospherists. Use of the term was at its relative maximum during the early $1950 \mathrm{~s}$ when about $35 \%$ of all published papers on ionospheric physics (Manning, Bibliography of the lonosphere, Stanford University Press, Stanford, California, 1962) had the word ionosphere or a form of it in their titles. This trend has reversed as other specialties have developed out of ionospheric physics and terms such as "magnetosphere" and "STP" (solar-terrestrial-physics) have come into common use to designate many subjects which formerly were included primarily within the specialty of ionospheric physics.

\title{
Transformation and tumorigenicity
}

\section{from Robert Shields}

SOME recent observations on the properties of cells transformed by mammalian tumour viruses and their ability to cause tumours when injected into the commonly used nude mouse, raise several questions on the validity of treating these experimental systems as a model for real cancers.

Ever since the first mammalian cell cultures were transformed by tumour viruses a great deal of effort has been expended in attempts to understand the process of oncogenic change in vitro. Studies using a fow cell types and even fewer viruses have collected an enormous number of in vitro cellular properties that are often associated with tumorigenicity. These include changes in cellular morphology, increased cell autonomy, loss of densitydependent inhibition of growth, decreased dependence on high levels of serum in the culture fluid, increased agglutinability by plant lectins, changes in membrane composition, increased ability to grow in gel suspension (loss of anchorage dependence) and so on and so on. What is a pity is that much of the work on these propertics has been performed on established lines of virally transformed cells so it has been impossible to unravel which changes are caused by the virus and which have arisen through selection in culture.

One way around this problem has been to select at random clones of 3T3 or primary rat embryo cells recently infected with SV40 and examine each clone for various parameters of transformation (Risser and Pollack, Virology, 59, 477, 1974; Risser, Rifkin, and Pollack, Cold Spring Harbor Symp. quant. Biol., 39, 317; 1974). In this way it was hoped to find which parameters of transformed cells are related to the viral gene, which changes are related to each other, and which changes confer tumorigenicity.

The results from these experiments showed that the virus was able to elicit a whole spectrum of changes. The only alteration in some clones of $3 \mathrm{~T} 3$ cells was that they could grow in low concentrations of serum, and that they could grow to higher cell densities. These cells were negative for the virusspecified $\mathrm{T}$ antigen, no virus could be rescued from them and the cells could be fully transformed by reinfection with SV40. All this suggests that these changes may be caused by a hit and run action of the virus rather than by the continued presence of the viral gene.

The only in vitro cellular property that correlated with the ability of the cells to cause tumours in nude mice (which lack cell-mediated immunity), was their ability to grow in methocel suspension (anchorage independence) (Shin et al., Proc. natn. Acad. Sci. U.S.A., 72, 4435; 1975) and this property was in turn correlated with the ability of the cells to produce a protease that converts plasminogen in the serum to plasmin (Pollack et al., Proc. natn. Acad. Sci. U.S.A., 71, 4792; 1974). These experiments were performed with only two cell types and one transforming agent but many other reports have suggested a correlation between anchorage-independent growth and tumorigenicity (Freedman and Shin, Cell, 3, 355; 1974; Laug et al., J. natn. Cancer Inst., 54, 173; 1975).

The correlation between growth in suspension and tumorigenicity is far from absolute, however. Examination of epithelial cell lines derived from a number of human carcinomas show that some cells grow in suspension and fail to form tumours in nude mice, some anchorage-dependent lines are tumorigenic and furthermore there is no correlation between the ability to activate plasmin and either growth in suspension or tumorigenicity (Marshall, Franks and Carbonell, personal communication; Pearlstein et al., Cancer Res., 36, 1575; 1976; Jones et al., Int. J. Cancer, 16, 616; 1975).

These observations raise several questions not least of which is the suitability of the commonly used 'fibroblast' cells and their viral transformants as suitable models for real cancer, but also the use of the nude mouse as a means of detecting tumorigenicity.

There have been mutterings about established cell lines such as 3T3 for some time, especially because of their heteroploid karyotype. It is now clear, however, that the BALB/c3T3 cell line is frankly tumorigenic when attached to glass beads and innoculated into suitable hosts (Boone, Science, 188, 68 ; 1975). Moreover, the tumours formed are 'vasoformative sarcomas' (Boone et al., Cancer Res., 36, 1626; 1976) so it seems that these cells are not fibroblasts but arise from endothelial tissue. In fact, a great many cell lines established from a wide variety of tissues appear to be derived from the endothelial cells and pericytes of small blood vessels (Franks and Wilson, Eur. J. Cancer, 6, 517; 1970), so many of the different established cell lines may represent a very restricted sample of the variety of cell types in the body.

Studies of the incidence with age of a great many naturally occurring cancers in man lend support to the hypothesis that cancer cells arise after a small number of heritable changes have occurred in a normal cell. Presumably the altered cell becomes a successful cancer if these changes result in it being better able to proliferate than the cell type it comes from. There is no reason to suppose that the changes which confer a selective advantage on one cell type in one environment will confer selective advantage on another, nor even that selective advantage within a given tissue need arise through a unique series of steps; other pathways could be equally effective. As a consequence tumour cells from widely different tissues might be expected to have widely different properties when studied in vitro. After all what is good for the endothelial cell may not be so good for the bladder.

Such generalisations that have been drawn about the nature of neoplastic change from the use of cultured cells may simply reflect the small number of cell types examined and the even smaller number of oncogenic agents. 